focus, but each makes a useful contribution to a topic on which there is currently a dearth of material. Kieth Wright's book will no doubt serve as the introductory textbook for library school students and practitioners in the field for some time to come.Meredith A. Butler, State University of New York, College at Brockport.

Boss, Richard W. "Circulation Systems: The Options," Library Technology Reports 15:7-105 (Jan.-Feb. 1979). Single issue \$40. ISSN 0024-2586. (Available from: American Library Assn., 50 E. Huron St., Chicago, IL 60611.)

It is tempting to describe this report by Richard Boss on circulation systems as "Everything you ever wanted to know about ..." etc., but that simply isn't true, as the author would be the first to admit. It is primarily a survey of the features of existing systems. Of the one hundred and eight pages in the report, fifty-four are devoted to descriptions of existing circulation systems. After a few pages on manual and photocharging systems, which after all are still valid in many applications, the author turns to a description of automated systems. He briefly examines the systems of nineteen developers, mostly commercial but also including those of three universities and one public library. For each developer he lists addresses, telephone numbers, and a brief description of what the developer provides. The extent of the descriptions varies, depending on how much information the author could obtain. He attempts little evaluative comment on each one, observing that most of the applications surveyed do not yet have an operational history sufficient to provide much that is helpful.

The value of this report is rather limited because it is of necessity quite topical. The market for circulation systems is very dynamic and subject to rapid change. There is no clear leader in the field. So this report shares with earlier LTR reports in 1975 and 1977 a very short half-life. To some extent it is useful to compare what Barbara Markuson and William Scholz said in those earlier reports with what Richard Boss says in this one, but such comparisons are now largely of historical interest simply because the rapid pace of technological change has made most of their comments obsolete.

No one who is about to decide on what circulation system to purchase, as Richard Boss himself indicates, can totally rely on surveys like these. They are useful largely as an introduction to what products are available and as an indication of how someone should pursue an independent investigation.

It is on this latter score that Mr. Boss' work is of most value. The last third of his report is devoted to helpful advice on methods of investigation, solicitation of bids, evaluation of responses, and contract negotiations. As an example of one safeguard to follow, he includes the acceptance plan of the Tacoma Public Library, which recently acquired a rather comprehensive automated circulation system. He also attaches something that is frequently difficult to find but yields at a glance the relative success a developer may have enjoyed up to now: a list of the systems they have installed. Finally, he has some sage advice on the use of consultants and the balance that should be maintained between

\section{A.N.Z.A.A.S. CONGRESS}

Contributions in the sciences, social sciences and humanities. Between 400 and 900 individual papers each year, most not published anywhere else!

Now indexed in Chemical Abstracts and APAIS (Australian Public Affairs Information Service).

Proceedings of Annual Congresses of the Australian and New Zealand Association for the Advancement of Science, now available.

- from 1970 (42nd Congress) onwards, on diazo microfiche at $24 \times$ reduction

- with author index (1970-76)

- with author, title and KWOC indexes (1977 - )

$\bullet$ by standing order or singly

Contact: Technical Services Librarian University of New South Wales P.O. Box 1, Kensington. N.S.W. Australia 2033 
reliance on consultants versus developers versus making one's own independent judgment.

This report will not resolve many issues. Even Mr. Boss' attempt to define an idealized circulation system is subject to argument. Who can now say to what extent a circulation system should be a finding list or a partial surrogate for the card catalog in addition to keeping track of what is being circulated? No one knows. The answer is a function of cost, availability of equipment, perhaps even taste. Nevertheless, Mr. Boss' work will benefit those who are now confronted with an immediate decision on whether or not to buy a circulation system. It won't simplify the decision, but it can shorten and guide investigation.-Richard J. Talbot, University of Massachusetts, Amherst.

\section{ABSTRACTS}

The following abstracts are based on those prepared by the ERIC Clearinghouse on Information Resources, School of Education, Syracuse University.

Documents with an ED number here may be ordered in either microfiche (MF) or paper copy (HC) from the ERIC Document Reproduction Service, P.O. Box 190, Arlington, VA 22210. Orders should include ED number, specify format desired, and include payment for document and postage.

Further information on ordering documents and on current postage charge may be obtained from a recent issue of Resources in Education.

\section{Temple University Libraries in the Mid-}

Seventies: A Status Report. By Joseph Z.

Nitecki. Univ. Libraries, Temple Univ., Philadelphia, Penn. 1977. 51p. ED 163 893. $\mathrm{MF}-\$ 0.83 ; \mathrm{HC}-\$ 3.50$.

Present central library operations are discussed in terms of emerging needs and possible direction for future development. Library objectives include acquiring and organizing relevant records of knowledge and providing satisfactory information service standards. Issues relating to objectives include the library's involvement in planning developing educational programs, support of pro- grams offered, and a well-selected professional staff, strong in subjects relevant to library coverage and involved in continuing education. Library organization and structure are concerned with the centralization of library services within the university, and the functional arrangement of activities within the library. At present, Temple's library structure is a combination of centralized and decentralized services. Issues involving personnel are consultative management, professional self-governance, unionization, and affirmative action policies. The library's budget recommendations are based on a balanced budget principle, and library department heads participation. Collection development is based on stimulus-response buying and a system approach. Gradual computerization is taking place with a fully automated circulation system, OCLC, microforms, and semiautomated interlibrary loan. Future issues include cooperation and networking within the profession; cooperation and coordination within the university; and structural reorganization, development of long-range personnel programs, continuing automation, and additional library space.

\section{Application of a Library Model: A Case} Study of the Illinois Library and Information Network. Report No.8. By William B. Rouse and Sandra H. Rouse. Coordinated Science Lab., Illinois Univ., Urbana. 1978. 123p. ED 163 931. MF$\$ 0.83 ; \mathrm{HC}-\$ 6.01$.

This case study describes the application of an analytical library network model to data collected during April 1977. Models are developed for describing the intralibrary processing activities encountered at each of the resource libraries in the study, and alternative routing policies for referring requests among resource libraries are analyzed. A recommended routing policy is suggested that predicts an improvement in network probability of satisfaction and a slight decrease in writing time for roughly the same reimbursement cost experienced in April 1977. Understanding of the intralibrary processing activities is also useful for analyzing the impact of alternative technologies on network probability of satisfaction, processing time, and cost per request. Seven alternative technologies with various combinations of location and availability information are identified, and performance predictions for Illinois are estimated. Data tables are supplied; requests, tabulated by subject class and publication date, and recommended request routes for each system in the network are appended.

The Role of the University's Library Resources in Teaching and Learning in the 